\title{
Family Harmony and Psychological Adjustment among Gifted and Ordinary Student
}

\author{
Nabil Juma Al-Najjar, ${ }^{1 *}$ \\ ${ }^{1}$ Dept. of Psychology, Faculty of Education - Mutah University, Karak, Jordan \\ *Correspondence: Dept. of Psychology, Faculty of Education - Mutah University, PO Box \\ 61710 Mutah, Karak, Jordan. Tel: 962-798-011-404. E-mail: nabilnajjar@yahoo.com
}

Received: November 25, 2016 Accepted: December 13, 2016 Published: February 1, 2017

doi:10.5296/ije.v9i1.10365 URL: https://doi.org/10.5296/ije.v9i1.10365

\begin{abstract}
This study aimed to identify the relationship between the psychological and family adjustment among ordinary and gifted students.

The sample of the study comprised (100) students deliberately chosen to achieve the purposes of this study, two scales were developed which are (the psychological adjustment and the parental adjustment), the result of the study revealed:

- The degree of parental and psychological adjustment in the gifted and ordinary student is considered high.

- A statistically significant difference at $(\alpha \leq 0.05)$ between the parental and psychological adjustment in the ordinary and gifted students in favour of the gifted students.

- There isa correlation with statistically significance at the level of $(\alpha \leq 0.05)$ between the parental and psychological adjustment in the ordinary students, and a strong correlation relation with statistically significance in the gifted students.

- There is no difference in the degree of parental adjustment at $(\alpha=0.05)$ in the gifted students with the change in their economical level, father's educational level, number of family members, and class.

- There is a difference in the degree of psychological adjustment of $(\alpha=0.05)$ in the gifted students with the change in their economical level, favouring the higher level.

- There is no difference in the degree of psychological adjustment of $(\alpha=0.05)$ of the gifted students with the change in their father's educational level, number of family members and class.
\end{abstract}

Keywords: family harmony, psychological adjustment, gifted student 


\section{Background of the Study}

The study of personalities is considered as one of the important subjects, it is not limited to the study of one pattern of behaviour, and it is widened to include all of the processes that set up the basic and most fundamental properties which affects inevitably all of the aspects of their behaviours. Wither these properties are inherited or acquired, it also includes the current reality we live on which rendered the human beings to live in it as a stranger, isolated from his own self, within this chaos and tension which the modern life style is well known for, so he ignores all of his feelings and desires, and answers to the others desires, accepting such roles that doesn't fit his personality, therefore, the personality is considered a major pillar in the understanding of the human behaviour, and the life style that one takes up to calibrate between his own self-desires and the requirements to live in this environment.

In saying so, the gifted students are considered a very important national treasure, that it is the duty of societies to nurture and take care of them, to invest their gifts, in order to make these societies a better place, by taking part in its progress and prosperity, therefore, these gifted students are in need of nurture and attention as much as the ordinary students if not more, and the failure in helping them achieve the maximum of their potential and capabilities, could be considered as a catastrophe to themselves first, and to the whole society, it is the right of these students to get a fair educational opportunities that works best with their abilities and capabilities, it is for that that they are a special challenge to their teachers and families on the one side, and to the instructors on the other side (Rehani, 2002).

The western and developed countries have figured the importance of the gifted students and are providing the appropriate attention to these students, they have provided them with all they need, starting from the academic programs that discover them, help them overcome their problems and fulfil their needs, these countries try to exploit every means necessary to invest in these students in a major way considering that the human brain is what enriched these societies with inventions and scientific discoveries within many and multiple areas that aims to keep the wheel of progress and development going and finding solutions to the problems of those societies.

As the personality grows and evolves continuously since birth, and as the human being grows some of their traits start to appear gradually, as the emotions start to differentiate, the growth of the personality is not limited to increasing its type and traits, it's by training these traits, and accustoming them to fit the society and its requirements (Badran, 2004).

The human life in its essence is based on his social interaction with the others, the person who fits the most in the society shares in it to the maximum, and his personal relationships in that society is characterized by being deep, close and yet still independent at the same time, he has a high positive self-esteem, realizing its value without overrating, feeling secure and safe, realising his weaknesses and trying to amend them (Abu-Asa'd, 2010).And this social adjustment is apparent in all psychological and social aspects, in which the person and the society work together to achieve this adjustment (Abed-Alraheem, 1986). 
The process of reaching adjustment is not a fixed constant process which happens in a certain situation or a certain time, it is a contentious sustaining process where the individual is faced with a chain of non-ending problems, needs and situations that needs the appropriate behaviour, which leads to decreasing the tension and restoring the balance, because the individual is asked to maintain the balance and keep his relationship to his environment at equilibrium whenever this equilibrium is threatened by a stimulant, internal affecter or an external affecter (Peter, 2008).

As for the behaviour of the individual, it is consistent with the social values of that society, this adjustment might be viewed from a moral prospect, in the light of a moral code, or a set of rules that are acknowledged by the society, this adjustment comes to involve the cases of diminishing of power or health as well as the death of a wife or a spouse, as well as retirement and a decrease in income (Shathely, 2001)

\subsection{The Problem of the Study}

Adjustment is considered a very important issue to both individuals and societies, where adjustment is what makes the individual in equilibrium with himself as well as the others, which reflects on his life socially and psychologically with peace and comfort.

\subsection{The Purpose of the Study}

This study aimed at Family Harmony and Psychological Computability among Gifted and Ordinary Student.

\subsection{Questions of the Study}

1- What are the psychological and parental adjustment levels in both the ordinary and gifted students?

2- Is there a statistically significant difference at $(\alpha=0.05)$ in the psychological adjustment and parental adjustment between the ordinary and gifted students?

3- Is there a statistically significant relation at $(\alpha=0.05)$ between the psychological and parental adjustment in the ordinary and gifted students?

4- Is the parental adjustment at $(\alpha=0.05)$ in a sample of gifted students differs by the difference in the economical level, the father's educational level and the number of members in the family and class?

5- Is the psychological adjustment at $(\alpha=0.05)$ in a sample of ordinary students differs by the difference in the economical level, the father's educational level and the number of members in the family and class?

\subsection{The Importance of the Study}

This study's importance lies in that it is concerning the gifted and ordinary and how adjusted they are, parental and psychological, through explaining the relationship between the parental adjustment and the psychological adjustment, for its importance in detecting the parental and 
psychological adjustment in the gifted students, who are considered an important pillar in the society and an important factor in building and progressing it.

\subsection{Procedural and Conceptual Definitions}

Parental adjustment: a state where a good relationship for the individual with his family, through it the person can meet his needs while accepting what's imposed on him by the parental environment (Abed-Almouti, 2004).

And it's defined practically as the score the individual receives on the parentaladjustment scale that was developed for studying.

Psychological adjustment: the degree which the individual can hold itself and take criticism and depression with the ability to control the insecure worrisome feelings to stay away from tension and fear (Zahran, 1994).

Practically it is defined thescore the individual receives on the psychological adjustment scale that was developed for studying.

Excellence: the excellent student is defined as the student who achieve higher or gets a higher marks than the majority or the ordinary which is if he gets over $90 \%$ in his academic studies.

Practically it is defined as the students who show a higher excellence in the school performance and there general average is above $90 \%$ in the last school year.

\subsection{Theoretical Framework}

The concept of personality is one of the most complex and interlinking concepts in the study of psychology, it includes all of the physical, mental, moral and subconscious qualities, interacts with each other to make out who the individual is, and his interactions with a specific social environment, so the discussions concerning the definition of personality has been very wide in verity, from its nature and qualities, and the ideas about it showed a very wide differences, some of those definitions looks at the personality as viewed by others, in so describing the influence left by a group of physical psychological and internal qualities of an individual on others, another definition takes the personality as viewed and felt by the individual himself, and revolves around how the person feel his individuality and his own self-aware (Abu-Asa'd, 2010).

The study of the personality has taken up a very important share, up to the point that it has taken up as an independent subject within the study of the psychological field studies, where this subject is concerned with the different aspect of personality and how it grows, the factors influencing it, how it's measured, and the different theories that explained it. And when we talk about the personality, we must surly talk about behaviour, because every action, thought or matter of expression by a certain individual, is an indicator of his personality, and an expresser of what is felt internally, the dreams are an expresser to what's is going on in the subconscious, they represent the thoughts and suffering, and through those we can get hints on the pattern of the personality and its characteristics (Saleh, 2008). 
To know his own self is one of the most complicated problems faced by man since the beginning of time, some attempts are still made to identify the personality, a lot of opinions which supplied a lot of concepts about the nature of the human personality and its characteristics (Sufian, 2004).

Eysnenck (1970) defines the personality as it is that organized, fixed and sustained to some point of the person's mood, mind and qualities that sets the adaptation process of the individual with his environment.

The definitions of the personality takes special care with the individual as a part of the group, and how well he can be in harmony with the requirements of this environment, and ability to get along with the circumstances when needed, these definitions take in count the idea that states that for each of the environmental and social factors plays a role in the forming of one's personality, Grifiths defines the personality in the social frame as it is the collective of the individual characteristics which comes from his interaction with his society, and appears as a set of specific behaviours to deal with this environment (Alqathafy, 1996).

As for Carmiceal and Warren, they defined the personality as it is the mental organization of the human as a whole, at a certain stage of his growth, and it includes he psychological, physical, mood, morals and his opinions as well (Alsarkhy, 2002).

The individual who is in harmony psychologically and socially is characterised to have a fulfilled personality, and can balance between his needs and his moral attitude, interaction with his environment and can take the burden of the present for the future, he has an adjustment of behaviour and no contradictory, adjusted with the values of his society without giving up on his independence, has a normal healthy non-radical growth in his emotions, cooperative in his society. And as described by Maslow, the adjusted individual is a spontaneous, has spiritual expertise, accepting to himself, others and his society, has a cheerful soul, fond of creation, with intimate relationships and appreciate the others without being biased, tells the difference between the means and the goals, has morals that includes a wide area of life, has independence and a realistic prospect to the world, focusing on problems not himself, accepting to the common social manners and following them obediently (Sufian, 2004).

Adjustment : no doubt that the individual is not without problems or obstacles that stand in the way of him fulfilling his needs and goals which in the end makes him feel satisfied and settled, in so there is no individual without problems even if he reached a state of stability and secure, because the problems are a normal issue in the lives of humans in so he must face those problems and work on solving them in order to overcome them, In doing so he reflects an image of the healthy adjustment (Ali \& Abd-Alghani, 2004).

As the definition of adjustment implies the presence of a relationship with the environment that includes the ability to fulfil most human biological and social needs, the definition of adjustment includes all the variations and changes in the behaviour that are necessary in order to maintain harmony in the relationship with environment(Peter, 2008). 
Rabea' (2006) defines adjustment as a constant equilibrium between the creature and the environment which he lives in, or the state of harmonized relationship with the environment where the individual can fulfil his needs considering the surrounding environment's changes.

Adjustment is defined as a state of harmony between the individual and his environment and his ability to change his behaviour and habits when facing a new situation, or a financial problem, or moral one, or an internal conflict, or a change to fit and live through this new situation and return to harmony with the surrounding environment, and to be always ready for it, with the power to understand and adjust and bond with other individuals (Alrahou, 2005).

Adjustment family:- the family is considered the main unit in building the society, therefore the healthy holding family contribute to the forming of a healthy individual, as for the dismantled family, contribute in forming a troubled individual and therefore in the formation of multiple social problems, the healthy family helps each member of it to face the stress in life and deal with them efficiently and make its members feel secure and safe for they have a powerful healthy network that he can depend on it when he faces trouble, on the other hand in case of the dismantled family, the individuals became a burden to their relatives in the family and the house turns into a hideous place to be on, in that the children seek support outside the family and the parents seek fulfilling their needs outside the relationships within the family (Bnat, Megdady, Ghaith, Alshoubaki, Alrashdan and Darweesh, 2010).

The family is characterised to be the first social organised group that are linked with a set of internal organismal rules that sets the role of each member, the family is the main building unit of the society, depending on it are the rest of social structures, as well as it represents a ring of influence and affect to those structures, in so the healthy family as a social structure reflects positively on the rest of social structures, and its breakdown reflect negatively on those structures (ALjameely, 1993).

The family adjustment is defined as the parental happiness and it includes the parental stability, and the power to fulfil the family members goals and the health of the relationships between the parents, and having fun spending the quality time together, with love and trust amongst them (Mohammad, 2004).

Considered as an important factor in achieving the parental adjustment, fulfilling the basic needs of its members, wither it was a child of a grown man, either male or female, stating next are some of those factors (Alkandery, 1992).

1- The presence of a common goal for the entire family, and the power to contribute in the society welfare and making it a better place, and following the moral code of this society, and abiding them.

2- A mutual understanding between the parents about their relationship with their children, and to provide care and nurture to them without bias or favouring.

3- The contribution of the children in the family by realizing its needs and trying to fulfil them.

4- Economical safety and stability, and the appreciation of each member to what other members are doing to contribute in the purpose of parental happiness. 
5- The successful experiences in facing the problems that comes across the family's path.

6- The presence of both physical health and capabilities that allows all the family members to fulfil their responsibilities, and achieve the family's needs as a whole.

From these past definitions we can sum up a definition to the family adjustment as: having a harmony relationship between the family members that is characterized by love, trust and mutual respect to each member, and the healthy relationships between the family members to achieve happiness, safety, and parental stability.

In so we can say that, the psychological adjustment is the mean to reach the psychological healthiness and the proper adaptation in the individuals, and it is a dynamic continuous process that handles the behaviour and environment by changing and adapting till equilibrium between the individual and the society is reached, and what sets the successfulness of this adjustment by how successful the individual's methods to reach a state of equilibrium with his environment (Zahran, 1997)

The Properties of the Gifted Students:

There has been many researches that was done by scientists about the qualities and characteristics of the gifted, where they found the gifted to be unique in some ways than their peers in the same age periods, we can identify them from the ordinary peers by these characters, never the less any individual a child was it or an adult, not necessarily has all those qualities, in general the gifted are known to be more advanced mentally than the ordinary (Altantawy, 2008).

Many educational studies indicated that the gifted have many psychological, social and mental non-specific intervening characters, and can't be all present in certain individual that wins the title of the gifted, this means that recognizing the gifted entirely can't happen (Alsharari, 2015).

Also they are known to have a better physical abilities than their peers, as well as they show high mental functions, and high reading and language using capabilities, also in the mathematical and scientific abilities, as well as art and literature, and a realistic information in history and nations, they have their own interests, so they learn to read easier and read more and gain knowledge better than the rest of their ordinary peers, and have hobbies, they are confident for they get higher marks in the personality exams (Alsorour, 2003).

\section{Previous Studies}

A lot of related previous researches and studies were looked into, which were conducted in both Arabic and western societies, the most important studies which are relevant to the current study's variable were chosen, and up next are a view of these studies arranged chronologically from the most recent to the oldest which are :

Barahmeh \& Bnat, (2014) with the title of the relationship between the psychological adaptation and the causes that gifted student attend to the advanced centres, it aimed to define 
the relationship between the psychological adaptation and the causes that gifted student attend to the advanced centres. The researchers used 2 scales for the purpose of the study which are: the adaptively scale, the causes of student attending to the advanced centres which was developed by them, and the psychological adaptively scale (1996), the two scales were implemented on the study sample, which was 50 of the gifted students, they were chosen deliberately from the advanced centre in Ain Albasha in Blqaa' -Jordan, the results showed that the psychological adaptation is generally high amongst the students, and the parental adaptability is the highest, where the emotional adaptability was at the bottom as lowest, also it shows difference in the social adaptability in favour of the females, no significant differences between males and females in other adaptively areas.

Mkhemer, (2003) studies the psychological, educational and social needs of the gifted students from their prospective and the prospective of their teachers in the city of Gaza, Palestine. Which aimed to learn the difference in the educational and social needs from the prospective of their teacher, and the prospective of the gifted students, and to achieve the aim of this study the researcher used the descriptive and analytic method, the study sample consisted of 50 teachers, and 100 students were chosen by a simple random method from Alshaheed Arafat for gifted students in Gaza city, one of the most important results that there is many psychological social and mental needs which the gifted students require, such as mentoring training and guidance, and the lack of statistically significant differences between the responses of students and teachers in the specification of those needs.

Blackett \& Webb, (2013) conducted a study titled the social and psychological effects for being gifted in lights of the model (G SEN) which is the model for supporting gifted student's psychological and social needs, and it focused on the importance of the social and emotional aspects of being gifted. This study shown that the innate factors and capabilities for the gifted students is not enough to sharpen the talents, and the psychological and social need must be attended, for they are affecting their social and psychological growth, and that single, environmental, social and psychological factors work separately and then interacts at their mental superiority level, and this study shown that the needs should be met for the gifted while focusing on how the student think, feels and act altogether, and the methods of how they think and learn. And to shine a light on the challenges that face the gifted students.as the study also showed that the model (SENG) is known to attend to the gifted care and can attend their psychological and social needs for the gifted and talented individuals, through a 10weeks program, and his model includes beside the trainers in the school the parents to attend to their children their psychological and social needs.

AlAshoal, (2012) which was titled as the problem with the gifted students in Methak school, and the study sample was 52 students divided as 24 students in the elementary school level, and 28 students from the high school level, from the gifted top of the class students, which studied in the school of Methak, and the psychological problems in the ordinary class, this study found a statistically significant differences between the ordinary and the rate of occurrence of problems as whole and at each class alone, in favour of the high school students, and by a far margin. 
AlJlamdeh \& Ali, (2011) investigated "the personal, psychological and social to the gifted students from the prospective of the teacher and the gifted students in the kingdom of Saudi Arabia - a field study", the study sample were a group of 40 teachers of the gifted students teachers, as well as 60 gifted student, in both middle and high school in the area of AlQaseem in the kingdom Saudi Arabia, a scale was designed for the personal, psychological and social needs of the gifted students from the prospective of their teachers, and designed a scale for the personal, psychological and social needs of the gifted students, and the results shown that these personal, psychological and social needs comes in an average range to the gifted students.

Mansi, (2008) conducted a study titled the problems and the psychological needs that the middle school gifted and talented students have, the study sample consisted of 500 students of the middle school student in Alexandria, of which are 250 males and 250 females aged between 12-14 years. The researcher used the gift and talents tests and he also implemented the problem list for the middle school student. The study shown that the gifted male students have their own problems like (isolation, depression, spacing, having an odd and no widely acceptable opinions, feeling depressed when failing, scepticism and trust issues. Ass for the female gifted students their problems were (shyness, and the feeling of annoyance when not superior to others, spacing, jealousy, and to lose the ability to fill the free time), the results implied that the more gifted students suffer from problems less than their less creative peers, and that there is no significant differences in the psychological health problems between the gifted male students and the female gifted students, and that they have many unattended psychological need.

Fornia \& Frama, (2001) investigating the search for the psychological and social needs of the gifted students, where the theoretical analytical method, this study showed that working with gifted students has a certain speciality that sets it apart from others. And it also showed the importance that the counsels that works with the gifted students to have a certain knowledge of the social background, which requires a cooperation with the family to overcome social stresses of which the gifted students suffer. And to help the students build a new reality which could decrease the obstacles and the social withdrawal that this group faces. Through providing support and contentious education for them and increase the interaction with the family and the rest of the social groups that deals with the gifted students.

\section{Design of the Study}

This study depended on books and previous researches in building the theoretical frame, and acquiring studies that are relevant to the study's subject, as for the collection of this study's data it depended of the descriptive surveying method by the study's tools and analysing them to answer the study's questions. 


\subsection{Population and Sample of the Study}

\subsubsection{Population of the Study}

The society of the study consists of all the ordinary and the gifted in the eighth, ninth, tenth grade in the schools of Almazar Aljanobi karak Hashemite kingdom of Jordan, during the first semester of the year (2015/2016). The gifted students were 450 students both males and females, according to the statistics of the ministry of education's Almazar Aljanobi branch, as for the ordinary students they were (4180) student from both males and females.

\subsubsection{Sample of the Study}

The sample of the study consists of 100 male and female student of the gifted in the eighth, ninth, tenth grade and 100 male and female ordinary student in the eighth, ninth, tenth grade, the sample where chosen by a random stratified method.

\subsubsection{The Instrument of the Study:}

For the current study's purposes the following tools will be used:

\section{First: the parental adjustment scale:}

This scale was developed by reviewing the educational and psychological literatures, and the scales that was developed for the retired class, where we used the study conducted by (Seyam, 2010) and the study of (Alaa'dein, 2004) and to the book of (Shthaly, 2001),

The survey contained the information about the personal information, economic level, the father's educational level, the number of family members and the class member's number.

The survey in its original form consisted of 26 paragraph divided amongst the following points:

- The healthy relationships between family members: and this indicates the satisfaction and harmony between the retired and his family members, the paragraph that measures this are (1, $2,3,4,5,6,7,8,9)$.

- The harmony and love: and it indicates the degree of happiness and love felt by the retired within his family, and the paragraphs that measures this are $(10,11,12,13,14,15,16,17)$.

- The family stability: and it indicated how stable the family life of the retired, and the paragraphs that measure this are $(18,19,20,21,22,23,24,25,26)$

\subsection{The Validity and Reliability of the Current Study}

\subsubsection{Referees Validity}

The credibility of the testers were checked by handing the scale to a 14 testers from the study board members, and from different academic specialities related to the subject of the study, and from those who have substantial expertise in the area of education, counselling, scaling, psychology and sociology, and that to make sure that the paragraphs have credibility and are clear and well understood, in addition the researcher asked them to propose any suggestion 
they see fit to improve the survey as they see fit, and to perform any changes by addition or removal, or moving around paragraphs according to the testers opinions, and after implementing the primary sample, it was clear that some of the paragraphs had a low discrimination coefficient, in the lights of that, four paragraphs were edited and six paragraphs were removed, as for the paragraphs which $80 \%$ of the testers saw credible they were kept.

Construct Validity: the credibility of the internal structure of the paragraphs were checked by calculating the correlation coefficient between the grade of the paragraph and the total grade of the scale which the paragraph refers to, the correlation coefficient were of significance and accepted for this type of studies, the paragraphs $(18,21,22,23,25)$ have shown a weak correlation coefficients and therefore were excluded from the scale, as for the rest of the paragraphs, they have shown a statistically significant correlation coefficient, and that shows a good build of the paragraphs and they are accepted in this type of surveys.

\section{Second: the psychological adjustment scale:}

This scale was developed by reviewing the educational and psychological literatures, and the scales that was developed for the retired class, where we used the study conducted by (Seyam, 2010) and the study of (Alaa'dein, 2004) and to the book of (Shthaly, 2001), The survey contained the information about the personal information, economic level, the father's educational level, the number of family members.

The survey in its original form consisted of 60 paragraph divided amongst the following points:

\section{Referees Validity:}

The credibility of the testers were checked by handing the scale to a 14 testers from the study board members, and from different academic specialities related to the subject of the study, and from those who have substantial expertise in the area of education, counselling, scaling, psychology and sociology, and that to make sure that the paragraphs have credibility and are clear and well understood, in addition the researcher asked them to propose any suggestion they see fit to improve the survey as they see fit, and to perform any changes by addition or removal, or moving around paragraphs according to the testers opinions, and after implementing the primary sample, it was clear that some of the paragraphs had a low discrimination coefficient, in the lights of that, eight paragraphs were edited as Table (7) shown the number of paragraphs that were edited before and after editing, and ten paragraphs were removed as shown in the table (8), as for the paragraphs which $80 \%$ of the testers saw credible they were kept.

Construct Validity: the credibility of the internal structure of the paragraphs were checked by calculating the correlation coefficient between the grade of the paragraph and the total grade of the scale which the paragraph refers to, the correlation coefficient were of significance and accepted for this type of studies, the paragraphs $(5,7,12,21)$ have shown a weak correlation coefficients and therefore were excluded from the scale, as for the rest of the paragraphs, they have shown a statistically significant correlation coefficient, and that shows a good build of the paragraphs and they are accepted in this type of surveys. 
Correction and interpretation of the scales:

The scale correction is being conducted according to the fifth Likert scale were the responses are given grades on the scale as follows, (totally agree) gets 5 points, (agree) gets 4 points, (neutral) gets 3 points, (disagree) gets 2 points, as for the choice (totally disagree) gets a single point, in this case the researcher adjusted the following levels to account for the parental adjustment and the psychological adjustment (Sekaran, 1998/1992).

1-low 2-medium 3-high

And that by using the tool's categories which are four starting from:

(1-1.99), (2-2.99), (3-3.99), (4-5)

And each class was given a grade according to the following equation:-

Dividing the tool's category by the number of alternatives $4 / 5=0.8$, using that the grades are according to the following arrangement:

1 - Low $\rightarrow$ starting from 1 to less than $(1+0.8+0.8)$ which means (from 1 to less than 2.6).

2- Medium $\rightarrow$ from 2.6to less than $(2.6+0.8)$ which mean (from 2.6 to less than 3.4).

3 - High $\rightarrow$ from 3.4 to less than $(3.4+0.8+0.8)$ which means (from 3.4 up to5).

Reliability of the Instruments:

To ensure the stability of the study's tools, the content validity coefficient (Cronbach alpha) were applied to the tools; it was applied on a sample outside the study sample, and counted to 25 ordinary student $\mathrm{s}$ and 25 gifted students, in Table (1) shows the reliability coefficient of the surveyed sample.

Table 1. Reliability Coefficient of the Surveyed Sample

\begin{tabular}{cc}
\hline Scale & Cronbach's alpha coefficient \\
\hline 0.92 & Family harmony \\
0.83 & Psychological adjustment \\
\hline
\end{tabular}

Table (1) indicates that his reliability coefficient ranged between $(0.83-0.92)$ and it is accepted for this type of studies.

\subsection{Variables of the Study:}

1- Parental adjustment

2-psychological adjustment

\subsection{Statistical Analysis}

To answer the questions of the study, the following analyseswere used:

1- Using the means and the standard deviation to answer the first question.

2- Using the correlation coefficient to answer the first question. 
3- Using one way analysis of variance to answer the second question.

4- Using one way analysis of variance to answer the third question.

\section{Results of the Study}

The results related to the first question, "What is the grade of psychological and parental adjustment among the gifted and ordinary students"?

Table 2. Averages \& Standard Deviations for Ordinary and Gifted Students in the Psychological and Parental Adjustment

\begin{tabular}{llccc}
\hline Field & Student & numbers & Mean & $\begin{array}{c}\text { standard } \\
\text { deviation }\end{array}$ \\
\hline Psychological adjustment & ordinary & 100 & 3.6647 & 0.4796 \\
& Talented & 100 & 3.8717 & 0.3711 \\
Compatibility of domestic & ordinary & 100 & 4.1860 & 0.4840 \\
& Talented & 100 & 4.4430 & 0.5066 \\
\hline
\end{tabular}

We can see from Table (2) that there are apparent differences in the averages.

That the psychological adjustment in the ordinary students came at a high level

That the psychological adjustment in the gifted students came at a high level

That the parental adjustment in the ordinary students came at a high level

That the parental adjustment in the gifted students came at a high level

The results related to the second question "Is there any statistical significant difference at $(\alpha=0.05)$ in the parental adjustment and the psychological adjustment between the ordinary and gifted students"?

To answer this question the averages and the standard deviations were calculated and $\mathrm{T}$ test were performed to 2 independent samples, and the results are shown in the tables (3), (4).

Table 3. Averages \& Standard Deviations for Ordinary and Gifted Students in the Psychological and Parental Adjustment

\begin{tabular}{ccccc}
\hline Domain & Student & Numbers & mean & standard deviation \\
\hline Psychological & ordinary & 100 & 3.6647 & 0.4796 \\
Adjustment & Talented & 100 & 3.8717 & 0.3711 \\
Family & Ordinary & 100 & 4.1860 & 0.4840 \\
adjustment & Talented & 100 & 4.4430 & 0.5066 \\
\hline
\end{tabular}


We can see from table (3) that there are apparent differences in the averages in the psychological and parental adjustment between the gifted and ordinary students, and to check that these differences are statistically relevant, a T- test were performed to 2 independent samples, and the results are shown in the tables (4).

Table 4. (T) Test for Two Independent Samples of the Difference in the Psychological and Family Compatibility between Ordinary and Talented Students

\begin{tabular}{rcccc}
\hline \multicolumn{1}{c}{ Field } & T. calculated & $\begin{array}{c}\text { degrees of } \\
\text { freedom }\end{array}$ & $\begin{array}{c}\text { significance } \\
\text { level }\end{array}$ & significance \\
\hline Psychological & -2.41 & 198 & 0.05 & 0.018 \\
Family & -2.59 & 198 & 0.05 & 0.011 \\
\hline
\end{tabular}

Table (4) shows that the results of -T- test reached the levels of the statistical level of $(\alpha=0.05)$ in both the psychological and parental adjustment, which reveals a statistically significant differences at the level of $(\alpha \leq 0.05)$ between the psychological adjustment in the ordinary and gifted students favouring the gifted students

And that a statistically significant differences at the level of $(\alpha \leq 0.05)$ between the parental adjustment in the ordinary and gifted students favouring the gifted students.

The results related to the third question, "Is there any statistical significant differences at $(\alpha=0.05)$ between the psychological and parental adjustment in the gifted and ordinary students"?

To know the existence of a correlation relation between the parental adjustment and the psychological adjustment and how strong this relation is and to know the statistically significance, the correlation coefficient (Berson) between the psychological and parental adjustment as shown in table (5).

Table 5. Correlation Coefficient between Psychological and Family Adjustment for Ordinary Students, and Gifted

\begin{tabular}{cccc}
\hline family adjustment & $\begin{array}{c}\text { psychological } \\
\text { adjustment }\end{array}$ & $\begin{array}{c}\text { Pearson correlation } \\
\text { coefficient }\end{array}$ & Significance \\
\hline Ordinary & Ordinary & $0.378^{* *}$ & 0.007 \\
Gifted & Gifted & $0.320^{* *}$ & 0.001 \\
\hline
\end{tabular}

** Significant at level (0.01)

* Significant at level (0.05)

The results in table (5) indicate a strong statistically significance correlation relation at the level of $(\alpha \leq 0.05)$ between the psychological and parental adjustment for ordinary students and the psychological and parental adjustment in gifted students.

The results related to the fourth question, "Are there any statistical difference in the parental 
adjustment at $(\alpha=0.05)$ at the sample of gifted due the economical level, the educational level, the number of family members and the class members number"?

To answer this Question use of the four way analysis of variance, and that to know the difference in the economical level, and the father's educational level, the family member's number and the class member's number $m$ at the level of the parental adjustment as shown in table (6)

Using of the four way analysis of variance showed that there are statistically significance differences in the parental adjustment in gifted students.

Table 6. Impact of Economic, Father Qualification, Number of Family Members and Grade of Family Adjustment

\begin{tabular}{ccccccc}
\hline $\begin{array}{c}\text { sources of } \\
\text { variation }\end{array}$ & $\begin{array}{c}\text { sum of } \\
\text { squares }\end{array}$ & $\begin{array}{c}\text { degree of } \\
\text { freedom }\end{array}$ & $\begin{array}{c}\text { Mean } \\
\text { squares }\end{array}$ & $\mathrm{f}$ & $\begin{array}{c}\text { Significance } \\
\text { level }\end{array}$ & $\mathrm{P}$ \\
\hline $\begin{array}{c}\text { economic level } \\
\text { father }\end{array}$ & 0.763 & 1 & 0.763 & 4.034 & 0.079 & 0.05 \\
$\begin{array}{c}\text { Qualification } \\
\text { Family }\end{array}$ & 0.188 & 3 & 0.063 & 0.331 & 0.804 & 0.05 \\
$\begin{array}{c}\text { Members } \\
\text { Grade }\end{array}$ & 0.1468 & 11 & 0.124 & 0.658 & 0.746 & 0.05 \\
TOTAL & 682.762 & 100 & 0.074 & 0.390 & 0.689 & 0.05 \\
\hline
\end{tabular}

Table (6) shows that there is no difference in the degree of parental adjustment at the level of $(\alpha=0.05)$ in the sample of gifted student with the change in their economical level.

And that there is difference in the degree of parental adjustment at the level of $(\alpha=0.05)$ in the sample of gifted student with the change in the father's educational level.

Also that there is no difference in the degree of parental adjustment at the level of $(\alpha=0.05)$ in the sample of gifted student with the change in the number of family members.

As well as that that there is no difference in the degree of parental adjustment at the level of $(\alpha=0.05)$ in the sample of gifted student with the change in the school grade they are in.

The results related to the fifth question, "Are there any statistical difference in the psychological adjustment at $(\alpha=0.05)$ of the gifted due to the economical level, the educational level, the number of family members and the class members number"?

To answer these Questions T-tests were used to tell the difference between the averages, and that to know the difference to know the effect of each of the following: the father's educational level, the family member's number and the class member's number in the degree of psychological adjustment as shown in table (7).

Analysing the T-tests result showed that there are statistically significance differences in the parental adjustment in gifted students. 
Table 7. Impact of Economic, Father Qualification, Number of Family Members and Grade of Psychological Adjustment

\begin{tabular}{lcccccc}
\hline \multicolumn{1}{c}{$\begin{array}{c}\text { sources of } \\
\text { variation }\end{array}$} & $\begin{array}{c}\text { sum of } \\
\text { squares }\end{array}$ & $\begin{array}{c}\text { degree of } \\
\text { freedom }\end{array}$ & $\begin{array}{c}\text { Mean } \\
\text { squares }\end{array}$ & $\mathrm{f}$ & $\begin{array}{c}\text { Significance } \\
\text { level }\end{array}$ & $\mathrm{P}$ \\
\hline $\begin{array}{l}\text { economic } \\
\text { level }\end{array}$ & 2.354 & 1 & 2.354 & 15.358 & 0.004 & 0.05 \\
$\begin{array}{l}\text { father } \\
\begin{array}{l}\text { Qualification } \\
\text { Family }\end{array}\end{array}$ & 0.852 & 3 & 0.284 & 1.853 & 0.216 & 0.05 \\
$\begin{array}{l}\text { Members } \\
\text { Grade }\end{array}$ & 3.694 & 11 & 0.336 & 2.191 & 0.138 & 0.05 \\
TOTAL & 0.255 & 2 & 0.128 & 0.833 & 0.469 & 0.05 \\
\hline
\end{tabular}

Table (7) shows that there is a difference in the degree of psychological adjustment at the level of $(\alpha=0.05)$ in the sample of gifted student with the change in their economical level, favouring the better economical level.

And that there is no difference in the degree of psychological adjustment at the level of $(\alpha=0.05)$ in the sample of gifted student with the change in the father's educational level.

Also that there is no difference in the degree of psychological adjustment at the level of $(\alpha=0.05)$ in the sample of gifted student with the change in the number of family members.

As well as that there is no difference in the degree of psychological adjustment at the level of $(\alpha=0.05)$ in the sample of gifted student with the change in the school grade they are in.

\section{Recommendations}

Based on the findings of this study, the researcher recommends the following:

1. Courses for gifted students to identify issues facing them.

2. The sessions for families of gifted students ' psychological problems and family recognition.

3. Teacher awareness of the importance of gifted students to maintain family and psychological adjustment.

4. Look at other variables pertaining to gifted students.

\section{References}

Abdul Muti, H. (2004). The family and the problems of children. Egypt, Cairo: Dar Al-Sahab for publication and distribution. [In Arabic] 
Abdul Rahim, A. (1986). Educational psychology and social compatibility (2 ${ }^{\text {nd }}$ ed.). Cairo: Egyptian Renaissance Library. [In Arabic]

Abu-Assad, A. (2010). Personality Psychology. Jordan, Irbid: the modern world of books. [In Arabic]

Aladdin, J. (2004). Psychological adjustment for retires older Jordanian employees and workers of both sexes. Mutah Journal for Research and Studies, Mutah University, 7, 19. [In Arabic]

Algelamdh, F., \& Ali, N. (2011). Personal, social and psychological needs of the students from the teachers and students gifted of view: a field study in Saudi Arabia. Magazine Science Educational Studies, 19(1), 91-140. [In Arabic]

Al-Kandari, A. (1992). Psychology of family (2 ${ }^{\text {nd }}$ ed.). Kuwait, Alfalah library. [In Arabic]

Alsrge, I. (2002). Behavior and character building among Western theories and between the Islamic perspective. Amman: Ministry of Information and Culture. [In Arabic]

Badran, A. (2004). Personality. Egypt, Mansoura: Aleman Library. [In Arabic]

Banat, S., \& Brahmeh, M. (2014). The relationship between psychological adjustment and the reasons for admission to gifted and talented students entrepreneurial centers: a field study in a leading position in the Ain Al-Basha Al-Balqa governorate. Damascus University Journal, 30(1), 476-510. [In Arabic]

Banat, S., Yousef G., Suad Sh., Naifeh R., \& Izz D. (2010). Family counseling. The National Council for Family Affairs.

Blackett, R., \& Webb, J. (2012). The Social-Emotional Dimension of Giftedness: The SENG Support Model. The Australian Journal of Gifted Education, 20(1), 5-14.

Chadli, Abdul Hamid (2001). Mental health and Sklogih Alchksah.t 2 University Library, Cairo. [In Arabic]

Eysenck, H.J. (1970). The Structure of human Personality, London, methueh.

Fonia, G., \& Frame, M. (2001). The social and Emotional Needs of Gifted Children: Implication. The family journal councling and therapy for couples and families, 9(4), 384-390. http://dx.doi.org/10.1126/10.1177/1066480701094005

Jumaili, K. (1993). Contemporary trends in the study of family and childhood. Egept, Alexandria: Modern university office. [In Arabic]

Mkhmar, S. (2013). Psychological, social and educational needs of gifted students from the perspective of teachers in Gaza City. Al-Aqsa University magazine - humanities, 1(1), 133. [In Arabic]

Muncie, M. (2008). Mental health problems creators of junior high school students in the creativity of Higher Education. Journal of Studies - Educational Sciences, 22(6). 
Peteros, P. (2008). Adjustment and mental health of the child. Jordan, Amman: Dar Almaseera publishing and distribution and printing. [In Arabic]

Rabee, M. (2006). Mental Health assets (6 ${ }^{\text {th }}$ ed. ). Egypt, Cairo: Dar strange for printing and publishing. [In Arabic]

Raho, J. (2005). Basics in psychology. Libnan, Beirut: Arab Scientific Publishers. [In Arabic]

Rihani, S. (2002). Ideas of rationality and irrationality of gifted and talented students. Jordanian Psychological Association conference.University of Jordan, Amman, Jordan. [In Arabic]

Saleh, Mamoun. (2008). Personal Bnawiha, composition, patterns, discomfiture. Jordan, Amman: Dar Osama. [In Arabic]

Sekaran, Uma. (1998). Research methods in management-entrance building research skills. (Translation: Ismail Ali Bassiouni, Abdullah Bin Sulaiman'Azzaz). Saudi Arabia, Riyadh: scientific publication and printing presses. (Originally Published 1992).

Sharari, Jazi, \& Al odeh, B. (2015). Social and emotional needs of academically gifted students in Al-Jouf University and its relationship to the academic level and specialization.Unpublished MA, College of Graduate Studies, University of Jordan. [In Arabic]

Siam, S. (2010). Personality traits and their relationship to the Psychological Adjustment of the elderly in the Gaza Strip. A master theses that is not published .College of Education, Al-Azhar University of Gaza-Palestine. [In Arabic]

Sufyan, N. (2004). Manual in personal counseling Alnevsa. aatrak: Cairo. [In Arabic]

Zahran, H. (2005). Mental health and psychotherapy ( ${ }^{\text {th }}$ ed.). Egept, Cairo: the world of books. [In Arabic]

\section{Copyright Disclaimer}

Copyright for this article is retained by the author(s), with first publication rights granted to the journal.

This is an open-access article distributed under the terms and conditions of the Creative Commons Attribution license (http://creativecommons.org/licenses/by/3.0/). 